Two Ways of Articulating Heterogeneity in Korean American Narratives of Ethnic Identity

M. Agnes Kang, University of Hong Kong (makang@hkucc.hku.hk) Adrienne Lo, University of California, Los Angeles (alo@ucla.edu) 
Two Ways of Articulating Heterogeneity in Korean American Narratives of Ethnic Identity ${ }^{*}$

\begin{abstract}
This paper explores the role of language in constructing relational identities among 1.5and second-generation Korean Americans. Using the methodology of discourse analysis, we reveal two ways of articulating social divisions within the Korean American community among 1.5- and second-generation Korean Americans in Los Angeles. We analyze how their narratives present different ideologies about identity as: 1) an attribute determined by factors not under an individual's control or 2) an observable accomplishment, capable of being easily modified by individual choice. We analyze the discursive features of these two discourses, which we call the discourse of dispositions and the discourse of agency, and we discuss the implications of this research for theories of race and ethnicity.
\end{abstract}




\section{Approaches to Ethnic Identity}

Studies of white Americans have generally argued that whites have control over what ethnicity they choose and the role that such ethnicity plays in their lives. ${ }^{1}$ In this model, ethnicity for whites is voluntary, self-ascribed, and symbolic. ${ }^{2}$ Race, on the other hand, is commonly taken to refer to a group whose characteristics are seen as both inherent and as imposed by others:

First, race typically has its assignment, in the classifications that outsiders make. Ethnicity often has similar origins, but it frequently originates in the assertions of group members themselves...There are exceptions to the rule of racial assignment .... Most racial categories, however, have been constructed first by those who wished to assign them to someone else; race has been first and foremost a way of describing 'others,' of making clear that 'they' are not 'us.'

Studies of non-white immigrants have analyzed the tension between these two kinds of positioning. For example, Waters notes that society's positioning of West Indian immigrants within a racial category of "Black" affects the conditions under which they are able to successfully invoke and be identified with an ethnic category such as "Haitian."4 This opposition between self-ascribed "ethnic options" and other-imposed "racial labels" has been further complicated by those who draw a distinction between externally defined (e.g. other-imposed) “ethnic categories" and internally defined (e.g. self-ascribed) "ethnic groups."5 
In attempting to untangle the ways in which Asian Pacific Americans orient themselves with respect to categories like "Korean" versus "Asian American," different scholars have mapped these terms onto different ends of the voluntary versus involuntary dichotomy. Espiritu, for example, looks at how a category like "Asian American" arose from non-Asians categorizing all Asians as being alike, and then became a mobilizing point around which Asian Americans united in an effort to gain political power. ${ }^{6} \mathrm{Her}$ work illustrates how other-imposed categories can be transformed into self-ascribed ones over time. Tuan argues that second- and third-generation Chinese and Japanese Americans "may prefer to define themselves in ethnic terms (e.g. as Chinese or Japanese)...but, on the other hand, may find themselves being defined in generally racial terms as Asian-Americans" [italics in the original]. ${ }^{7}$ Kibria's discussion of secondgeneration Chinese and Korean Americans, in contrast, argues that what is "Korean" or "Chinese" is viewed as primordial or given, through the metaphor of "blood," and that it is in fact one's identity as "Asian American" that comes to be seen over time as selfconscious or non-imposed. ${ }^{8}$ Scholars such as Song have criticized these works for relying on an overly artificial distinction between "race" and "ethnicity," noting that in participants' everyday lives, such distinctions may in fact be "slippery and blurred." 9 In these cases, the voluntary versus involuntary and self-ascribed versus otherimposed categories usually map onto each other, so that individuals are portrayed as having a choice over their identity within an ethnic community, but less of a choice outside of it. This recontextualization of categories from primarily self-ascribed to primarily other-ascribed, or vice versa, is usually talked about in terms of the "racialization" of ethnic categories, or the "ethnicization" of racial ones. These attempts 
to link specific words (like "Korean," "Chinese," or "Asian") to specific kinds of ideologies about self- and other-positioning stem from an understanding that while individuals' own positioning may change over time, the meanings of the words themselves remain stable.

In this paper, we would like to add a new dimension to this debate by arguing that it is not so much the terms themselves that point to different concepts of identity positioning, as it is the discourses in which they are embedded. While other scholars have looked at the tension between self- and other-positioning as one which is linked to the opposition between "ethnic" (e.g. "Korean") versus "racial” (e.g. "Asian American”) terms, we demonstrate that these kinds of tensions operate within what is usually conceived of as a single ethnic community. In our interviews with second- and 1.5generation Korean Americans in Los Angeles, we found that some participants would use a term such as "Koreanized" to point to a voluntary, self-ascribed, mutable identity while others would use that same term to talk about an identity which was conceived of as fixed and unchanging. Moreover, in moving towards a conception of identity as primarily changeable, participants also demonstrated an increasing attention to the negotiated nature of identity as achieved between participants, through an active attempt at signifying a particular identity on the one hand, and through a recognition of that identity on the other. Taking a discourse analytic approach to identity allows us to understand how participants' conceptions of identity as primarily fixed versus primarily changeable are not necessarily linked either to a change in the terms of self-definition (e.g. moving from an identity as "Korean" to one as "Asian American"), or to interactions within an ethnic community versus outside of it. Instead, different ideologies about the fixed nature 
of identity operate within the Korean American community, in narratives told by Korean Americans about Korean Americans.

In our examination of narratives about social positioning within the Korean American community told by 1.5- and second-generation Korean Americans in Los Angeles, we found two discourses of identity. One, which we call the discourse of dispositions, situated individuals' positioning within the Korean American community as being linked to states of mind, beliefs, and values which were depicted as inherent and not readily changeable. The second, which we call the discourse of agency, linked identities to easily modifiable and observable practices. These two discourses were not characterized by their use of specific terms (e.g. "Korean" as opposed to "Asian American" or "Americanized" as opposed to "Korean Korean") but instead by different kinds of discursive positionings and linguistic features, such as nouns, verbs, and adjectives. By looking in-depth at the emergence of these two discourses in talk by Korean Americans about Korean Americans, we hope to show on a micro-interactional level how participants themselves conceptualize heterogeneous identities within a Korean American community. This glimpse of how language "does things with words," ${ }^{10}$ we hope, will offer a new methodological approach to understanding the lived experience of heterogeneity or "the existence of differences and differential relationships within a bounded category" in the "third spaces" 12 that Asian Pacific Americans create and inhabit.

\section{A Discourse-Analytic Perspective}


Our approach to analyzing the interviews we conducted is centered in discourse analysis of narrative. ${ }^{13}$ While this kind of analysis relies upon the detailed examination of the language of a few select speakers, we present these samples as illustrations of a more broadly robust patterning that we found to be true across speakers. We recognize that identities are multivalent, situated and negotiated between participants. Moreover, individuals' positionings can change over time and depend on whom one is speaking with. By looking at how different individuals locate themselves in relation to the dichotomy of self-ascribed choice versus other-ascribed imposition, we hope to demonstrate what a detailed study of language can add to our understanding of identity.

This approach focuses on the implicit theories that narratives contain that may not be articulated explicitly or may not be accessible to the narrator herself, but nonetheless encapsulate ways of viewing the world. ${ }^{14}$ Capps and Ochs further explain the mediating power of narratives:

How a teller sculpts her tale- the grammatical form and the sequencing and intertwining of pieces of setting, enigmatic experiences, and outcomes-is not a focal point but rather a medium for exposing a deeper story. Stories can offer a powerful medium for gaining insights not fully accessible to the narrator. ${ }^{15}$

Our analysis thus attempts to go beyond approaches which simply attribute a more "American" identity to those who self-identify as "Korean American" on surveys. We hope to show that the beliefs that Korean Americans hold about ethnic identity are not 
limited to explicit assertions about such identities; underlying assumptions about the nature of identity are also revealed covertly through the kinds of language they use.

More specifically, our approach concentrates on the indexical aspects of language. We do not believe that the terms our interviewees use merely label pre-existing differences in the world; instead, by pointing indexically to features of the surrounding context, ${ }^{16}$ they create and define that world by their use. Duranti explains this distinction:

To say that words are indexically related to some "object" or aspect of the world out there means to recognize that words carry with them a power that goes beyond the description and identification of people, objects, properties, and events. It means to work at identifying how language becomes a tool through which our social and cultural world is constantly described, evaluated, and reproduced. ${ }^{17}$

These two discourses, therefore, reflect how people choose to talk about identity but are not necessarily objective properties of what people are or do. ${ }^{18}$ Our focus in this paper is not on whether these ontologies of ethnic identity are, in fact, "real" or whether the characterizations that our interviewees make about different types of people correspond, in fact, to social reality. ${ }^{19}$ Our analysis is not based on the specific terms interviewees used, for we found that the same term could be used in different ways. We do not offer definitions of what specific terms may mean, either. ${ }^{20}$ Instead, by examining the kinds of verbs, adjectives, and subject positions Korean Americans used to talk about social categories, we reveal two distinct narratives of ethnic identity which seem to hold true across participants irrespective of the specific terminology they use. 


\section{Methodology}

Interviews were conducted in Los Angeles between 2001 and 2003 by the second author, audiorecorded, and digitized for transcription. Interview excerpts in this paper are transcribed according to simplified transcription conventions, without marking pauses, overlap, or backchanneling (e.g. "mmhm," "uh huh") from the interviewer. An ellipsis between parentheses (...) indicates the presence of intervening talk. Excerpts where the hearing is uncertain are enclosed in parentheses, e.g., "(a little less).” Words in Korean are transcribed according to the Yale romanization system. All names used are pseudonyms.

Subjects for the study ranged in age from their late teens to twenties. Interviewees included Korean Americans who were born in the US, those who immigrated, longtime residents of Los Angeles, and recent arrivals. They were solicited through advertisements that offered students credit in psychology or a chance to win $\$ 100$ for participating in a study; research assistants who canvassed dormitories; personal contacts at a large Korean American church; and students who were taking a class on Korean Americans. We attempted to seek out not only individuals who were actively involved in Korean American organizations, but also those who were not linked to any organized group. A total of 18 subjects were interviewed, resulting in approximately 200 pages of transcripts.

\section{Narratives of Ethnic Identity}

Identity labels 
Originally, we conceived of this study as a way to understand the multitude of terms for different kinds of people that circulate within the Korean American community. While past work on the Korean American community has looked primarily at social divisions in terms of "generation," we found a number of other words commonly used by Korean Americans to talk about different kinds of Korean Americans. In addition to terms like “1.5 generation" and "second generation," our interviewees also used words like "Americanized," "whitewashed," "Korean Korean," "American Korean," "Koreanized," "Westernized," "Korean-washed," and "fob." Korean American community; Korean Americans who did not spend much time with other Korean Americans often did not know some of the terms, or did not have strongly held ideologies that such terms denoted specific types of people.

But when we tried to get interviewees to articulate what such terms meant, we found that different people seemed to use them in different ways. For example, when asked to define the term "Koreanized," some Korean Americans focused on specific cultural practices and traditions inherited from Korea, such as birth and death rites or the celebration of New Year's Day:

Adrienne: So what does it mean to be Koreanized?

Laura: $\quad$ Koreanized as in like um learning how to speak Engli-

Like Korean really well?

Um studying the culture um just celebrating like the Korean events

Such as like you know tokil

uh- paykil paykil is like a 100-day celebration 
You know when you're born

Stuff like um

Well we don't do this that much any more

But when your relatives pass away

You'kind of give respect to them

Like every year

On the day they died

And like you just have this family reunion

Where you just bow to your elders and stuff like that

Um stuff like New Year's I don't know New Year's Day

We have like a lot of you know

Like the elders give money to the younger kids and stuff like that Adrienne: $\quad$ Right $^{22}$

This account of what it means to be Koreanized links it to ritual practices performed at special events. Being Koreanized, in this account, is not really an aspect of daily life so much as it is a kind of symbolic ethnicity revolving around practices which are not even done "that much any more.",23

Others in this same community, however, located being Koreanized as an everyday lived experience, publicly accessible to others through the practices of listening to certain kinds of music or speaking Korean. In these narratives, being Koreanized is not about isolated ritual practices but is part of daily life:

Mike There are certain traits that 
uh more Koreanized people do

That Korean Americans they like won't do

Like listen to Korean music

You know

Me and a lot of my friends we used to listen to Korean music

But as you got older you really don't like

Really listen to it anymore

But you know

More uh more Koreanized people will

They will um

still listen to Korean music like all the time

They'll speak Korean like $50 \%$ or more

English in like public areas or outside ${ }^{24}$

While the first kind of narrative links being Koreanized to the institution of the family, the second one focuses more on enacting being Koreanized among peers, through the consumption of popular culture. The term "Koreanized" was not the only one for which consensus on its meaning seemed elusive. Even the referent of a term like "Korean," we found, was not always apparent in everyday conversation ${ }^{25}$ :

Adrienne So do you have like a lot of Korean friends here? or do you um

Jungook Uh you mean Korean Korean friends

Or Korean American friends 
Or $1.5 \mathrm{~K}$ - ((laughing))

Which are you asking about ${ }^{26}$

By initiating what linguists call "repair" on the term "Korean friends," ${ }^{27}$ Jungook here demonstrates that the referent of "Korean friends" is not entirely clear; there are "Korean Korean friends," "Korean American friends," and "1.5 friends," and while all these could be classified as "Korean friends," each term points to a different kind of social type in this community. In seeking to understand the multiple kinds of crosscutting social divisions which characterize this community, we therefore found it more helpful to look not at the terms themselves, but at the discourses in which they were embedded.

\section{Discourse of Dispositions}

Narrating internal states

The first kind of narrative we will examine is one that we have labeled the discourse of dispositions. In this discourse, participants indexically link categories of identity to internal states of mind, dispositions, and comfort levels:

Helen

Jungook is Korean Korean because

A even though Jungook has an- uh an American name

Or whatever

like a w- tch Western hemisphere name name

He still goes by Jungook

Secondly yes as you said

It th- The accent yeah 
You prefer-

You're more comfortable talking Korean

You you like Korean food the best right

And those certain-

Um but w- what really makes you Korean Korean

is that you want to marry a Korean woman

like a Korean Korean woman who has Korean cultural values

not just the culture itself

but you esteem certain things as as like

I mean you're totally $\mathrm{K}^{28}$

Here, Helen describes Jungook by using verbs of volition, like "want," “esteem," "like," and "prefer," which characterize private states of emotion or belief. ${ }^{29}$ Jungook is not characterized by the actions he performs, but according to his subjectively experienced, interior preferences and desires.

In these narratives, participants frequently linked categories of identity to emotional states, like being "more comfortable" or "more warm," and also did not hesitate to attribute thoughts and beliefs to others:

Adrienne What does it mean to be Koreanized?

John I guess K- Koreanized meaning that um

y- you're more uh you're more comfortable with uh Korean Korean you know

Let's say like if you had a choice between being uh with the American 
folks

Korean American folks

That's purely

You know born here

Or with Korean generation

You mostly lean toward one or the other

Which side you're more you feel more comfortable with ${ }^{30}$

Adrienne: So what makes somebody a fob?

Julie: $\quad(\ldots)$

They're very warm

The way they think is just very Korean culture-based ${ }^{31}$

Here, essentializing concepts such as "mentality," "equality," "values," and "culture" figure prominently as explanatory rationales. These mentalities and beliefs are often linked to constructions of place, and to a structure of imagined timeless oppositions between what is "in Korea" as opposed to what is "in the United States," as shown in the two excerpts below:

Adrienne What's the main difference between the two groups?

John Actually I would have to say,

Thinking about it?

Cause the mentality is different 
The mentality

If you grew up in Korea, the mentality is definitely different ${ }^{32}$

Adrienne So what would be an example of being Americanized?

Gary Americanized meaning like uh

Such as in marriage?

Adrienne Uh. Uh huh.

Gary Marriage as uh in equality?

Like uh in the United States you know

They share uh they share

The uh husband and wife both share uh responsibilities and stuff

(because) they're Westernized

But in Korea you know it's different

If you ask equality

There's no equality you know

Men are superior superior to women ${ }^{33}$

The dichotomizing vision expressed by John and Gary is reminiscent of what Gupta and Ferguson identify as the "peoples and cultures" paradigm of anthropology, which portrays the world as being composed of separate peoples, each with their own distinct, bounded, and coherent ways of understanding the world and living within it. ${ }^{34}$ In this set of narratives, identity is linked to static and spatially localized cultures and to mentalities, beliefs, and values that are framed as culturally determined, unchanging ways of being. 


\section{Linguistic features of the discourse of dispositions}

Linguistically, the discourse of dispositions is characterized by verbs of volition, like “want," “esteem," "like," “feel," "think," and "prefer," which express preferences and desires. These narratives also focus on qualities like place of birth and accent, which are not depicted as readily modifiable but as permanent. In this discourse, membership in a group is categorical, not gradient; people are not depicted as "more Korean Korean" or "less Korean American" but as members of "one or the other" group.

\section{Discourse of Agency}

\section{Narrating observable actions}

The other kind of narrative that participants used we have labeled the discourse of agency. In this discourse, participants indexically link categories of identity to observable practices, such as listening to Korean music, speaking Korean in public, watching Korean soap operas, and wearing certain kinds of clothes. Whereas the first kind of discourse portrayed identity as a kind of primordial essence, determined by factors presented as not being under the control of individuals (such as growing up in a certain place and time), in this discourse identity is considered an agentive act that is largely under the control of an individual. The key differences between the two discourses are summarized in Table 1:

\section{Table 1:}




\begin{tabular}{|l|l|}
\hline & $\begin{array}{l}\text { states of emotion or belief (want to, be } \\
\text { more comfortable with, like, esteem) }\end{array}$ \\
\hline \hline Discourse of observable actions & $\begin{array}{l}\text { Discourse of preferences, wants, } \\
\text { desires, values, emotions }\end{array}$ \\
\hline \hline State (more transitory) & $\begin{array}{l}\text { Quality (relatively permanent and } \\
\text { inalienable) }\end{array}$ \\
\hline \hline $\begin{array}{l}\text { Gradient membership; adjectives modified } \\
\text { by more, so, really }\end{array}$ & $\begin{array}{l}\text { Categorical membership; one "or" the } \\
\text { other }\end{array}$ \\
\hline \hline $\begin{array}{l}\text { Identity as readily modifiable through } \\
\text { individual actions; highlights the role of the } \\
\text { observer }\end{array}$ & $\begin{array}{l}\text { Identity as not readily changeable, } \\
\text { linked to unvarying characteristics like } \\
\text { time of immigration }\end{array}$ \\
\hline
\end{tabular}

Mike, for example, explains how someone can "try" to be a member of one category as opposed to another by deliberately performing certain observable actions and by changing readily amenable features of her/his outward appearance:

Mike

So they try to emphasize their Korean side

Like say more Korean

Listen to more Korean music

Watch Korean soap operas all the time

Do certain things like that ${ }^{35}$

Sarah's narrative similarly notes that categories of identity are not necessarily linked to demographic factors like time of immigration or place of birth but are instead deliberate significations by subjects who "make the point of showing" their identity and "try" to present a certain identity “on purpose": 
Sarah I get really annoyed by fobby people actually ((laughing))

Because like wh-

Why do you have to like I don't know

Why do you have to ((quietly))

S-Say that you're so Korean

You are so proud of being Korean that

You make the point of showing that you are Korean

In front of everybody like ostentatiously

Like "Oh, I have to get bleached hair"

"I have to wear this shade of lipstick" or

(...)

Adrienne So um so somebody who's fobby do they

Do they try to be fobby? Like is it like

Sarah Yeah I know people who try to be fobby on purpose?

Because they they like it when people call them fobby

They're really proud of it?

(...)

Adrienne: So does being fobby have to do with where you were born

Or or when you came

Or it doesn't have so much to do with that?

Sarah: $\quad$ Um I don't think so because

Ok my some of my friends,

Um they were born here? 
But yet they they always go out of their way to make Korean friends

Or they

That's just who they prefer to be with?

So they start to dress like them they start to talk like them

They might have a little bit of accent or they might not or

But then it's just like their life style um

Just the way they dress

And the TV shows they watch ${ }^{36}$

These two portraits link identity to the performance of mundane everyday practices, or what Bourdieu called habitus. ${ }^{37}$ But whereas, for Bourdieu, habitus is largely determined by history and social class and inculcated through a lengthy process of socialization, the discourse of agency decontextualizes these practices from the persons they inhabit and highlights their performativity, as tokens amenable to conscious manipulation. ${ }^{38}$ The use of verbs like "try," "go out of their way," and "show," for example, suggests an intentional actor, or a performer in Goffman's sense, who strategically controls the outward signs of ethnic identity in an attempt to achieve the effect desired. ${ }^{39}$

\section{Linguistic features of the discourse of agency}

Whereas the discourse of dispositions concentrated on stative verbs like "want" and “esteem," which depicted individuals' mental states and preferences, the discourse of agency makes use of dynamic verbs, like "watch," "listen," "wear," or "talk," which 
"indicate action, activity, and temporary or changing conditions." ${ }^{40}$ Instead of linking categories of identity to imagined practices in Korea, like the discourse of dispositions, this discourse focuses on the everyday consumption of popular culture, in the form of music, clothes, hair, dress, and television. While Julie's narrative (p. 13) linked being a fob to the "the way they think" and to "Korean culture," for example, Sarah's narrative (pp. 17-18), like Mike's (pp. 16-17), highlight instead the ways that identities are made visible to others through certain practices, and are readily recognizable as such.

Indeed, the performative and temporary nature of identity in this discourse is indexed through an emphasis on adjective forms, such as "fobby" rather than noun forms, like "fob." Both Bolinger and Wierzbicka discuss the fact that nouns for people point to "types" or "categorizations" which are seen as permanent, conspicuous, and important. ${ }^{41}$ Bolinger argues that nouns produce a different effect than adjectives when used in this branding sense:

The noun OBJECTIFIES in a way the adjective cannot. A quality may come and go. If we are disappointed at Jane's lack of appreciation we can call her ungrateful, or solidify it a step further and call her an ungrateful person. But if we call her an ingrate we put the brand on her: the noun implies that the world puts people like this in a class by themselves [italics in the original]. ${ }^{42}$

Corresponding adjectives, in contrast, are descriptive, and do not categorize or define people as types. ${ }^{43}$ As Mike goes on to delineate the ways in which the processes of mimicry relate someone who "[is] kinda fobby" to someone who is a fob, ${ }^{44}$ the grammatical categories that he uses illustrate how being "kinda fobby" is provisional and changeable, but being a fob is not: 


\begin{abstract}
Adrienne So if you're born here
And you do those kinds of things

then you're acting uh

Mike

Well you're not you're not actually fobby

Well you're not a fob

But you're kinda fobby ${ }^{45}$
\end{abstract}

The contrast between the two discourses can also be seen in the way that each talks about language. The discourse of dispositions highlights accents, which are depicted as indelible, while the discourse of agency looks instead at practices of language, which are depicted as readily modifiable, like "the way you talk," "say[ing] more Korean," or speaking Korean in public. Yet these characteristics could be described otherwise; the people that Mike and Sarah portray in the two previous narratives could be described as having accents, and the people who are depicted as having accents in the earlier discourse could be described in terms of how much they choose to speak Korean in public. The ways in which these narratives selectively frame persons, however, as having more or less of a choice over their language reveals how each kind of discourse presents different ideologies about the nature of social identities.

The kinds of time-frames used in the two discourses are also different. Whereas narratives in the discourse of dispositions tend to situate individuals in terms of timeless, enduring contrasts between the U.S. and Korea and emphasize the importance of childhood socialization in shaping identities, the discourse of agency creates narrative 
time-frames which indicate that individuals' social positionings have changed, or are projected to change:

Sarah Like fobby can mean a lot of things

Just the way you dress

The way you talk

The the movies you watch

Like even if you're um not

Like even if you don't look fobby

But you always listen to Korean music

Listen- or watch Korean dramas

Watch Korean movies and that's all you talk about

Like you still

I still call the friends fobby who do that ${ }^{46}$

Mike There are certain traits that uh more Koreanized people do

That Korean Americans they like won't do

Like listen to Korean music you know

A lot-

Me and a lot of my friends we used to listen to Korean music

But as you got older you really don't like listen to it anymore

But you know more more uh Koreanized people will-

They still listen to Korean music like all the time

Um they'll speak Korean like $50 \%$ or more 
English in like public areas or outside ${ }^{47}$

Through words like "still," "used to," and "anymore," these narratives create timelines of progression which locate identity as a temporary kind of state, rather than a fixed quality. ${ }^{48}$ The word "still," for example, implies that more Koreanized people are projected to change their practices, as Mike and his friends already have. In addition, social identities in this discourse are gradable properties, where individuals can be "more" or "less" Koreanized. ${ }^{49}$

\section{Identities as accomplished between participants}

One important aspect of the discourse of agency is its focus on identities as negotiated between participants. While many models of identity seem to propose a dichotomy between identities which are either self-ascribed or other-imposed, the discourse of agency notes that identities are composed of both conscious attempts at self-ascription, as discussed above, and by other-recognition:

Sarah I still call the friends fobby who do that ${ }^{50}$

Mike We call people fobby

"You're acting fobby" and stuff

Just like the way they act and like

(...)

Honestly you can probably tell just by looking at the person 
Whether they're more Americanized

Or more Koreanized ${ }^{51}$

Evelyn: We joke cause one of my roommates is Korean

And she was born here you know

She's complete-

but she is into the whole Korean you know s-

Only listens to Korean music

Only watches Korean dramas

Only

And so we joke you know "You're a fob"

"You're a fob" 52

By highlighting the importance of the observer, who looks at someone and recognizes them as a certain kind of social type and/or explicitly brands someone else with an identity label, the discourse of agency foregrounds the interactive nature of the achievement of identity, requiring both an enactment of the signs of identity by one person and a recognition of that identity by another. ${ }^{53}$ The discourse of agency thus focuses on the externally visible and externally recognizable significations of identity.

\section{Resisting Identity Attributions}

Although the examples in our corpus that explicitly made reference to the role of both the observer and the actively signifying agent were produced within the discourse of agency, 
an interactional approach to identity can reveal how any interaction leaves open the possibility of contestation, whether it is of an interlocutor's own choice of identity or of the label they apply to another. In this last section of the paper, we would like to illustrate briefly how identity attributions can be resisted and contested in interaction. While the narratives discussed in the preceding sections were generally elicited in dyadic situations (that is, conversations between the interviewer and one interviewee), interviews conducted in triadic situations can reveal the strategies participants use to counteract others' assignments of them. For example, they can refuse to explain their labeling of others, as Jungook does when asked what "second generation" means:

Jungook Well Helen is like completely second generation so uh (( indecipherable speech ))

Adrienne Okay. Well what makes Helen What makes Helen second generation.

Jungook Ask Helen too ha ha ha 54

By not answering Adrienne's question and redirecting her to ask Helen, Jungook leaves the meaning of "second generation" deliberately opaque. Interlocutors can also pointedly resist others' attributions of them. After Helen presents her lengthy characterization of all the characteristics that make Jungook "Korean Korean," he attempts to turn the tables on her to get her to speak about herself, rather than about him:

Jungook Well what about you, Helen?

Adrienne ((laughter)) 
Helen No no no I'll tell you what

Jungook She knows so much about me and

$$
(\ldots)
$$

What about you?

She only talk about Korean Korean ha ha ha

And what else ${ }^{55}$

Lastly, they can self-identify in ways that make it apparent that these are in fact other-attributed terms:

$\begin{array}{ll}\text { Adrienne } & \text { So what about you } \\ \text { Jungook } & \text { Me? } \\ \text { Adrienne } & \text { Uh huh } \\ \text { Jungook } & \text { Well I guess I'm Korean Korean } \\ & \text { But I think well } \\ \text { Adrienne } & \text { Yeah I think so } \\ \text { Jungook } & \text { Yeah. Yeah w- } \\ \text { Adrienne } & \text { Why? } \\ \text { Jungook } & \text { Why are you Korean Korean yeah }\end{array}$

In this interaction, Jungook makes apparent his reluctance to self-identify first by not answering the question and initiating repair with the question, "Me?" When he, at last, 
reluctantly selects "Korean Korean," he then signals his distance from this term in several ways. By prefacing his turn with dispreferred markers like "well" and "I guess," he delays his answers while marking his epistemological doubt about the appropriateness of the term. Immediately after offering the term "Korean Korean," he qualifies it with, "But I think well" and "I think so," thereby reiterating his doubt about the term. In the end, he reveals that this is not really "his" term, but instead a heteroglossic term that other people use to talk about him. ${ }^{57}$

The complex ways in which Jungook presents a self-identification, but strongly distances himself from it, illustrate how the dichotomy between self-ascription and otherattribution is not as neat in real life as one might think. While the constraints of the interview situation and Adrienne's persistent questioning force him to select a label for himself, Jungook nevertheless performs this self-ascription in a way that makes it evident that this is not truly his "choice."

\section{Conclusion}

In unpacking the different linguistic ideologies that Korean Americans use to characterize social divisions within their ethnic community, we have demonstrated how, in certain cases, heterogeneity is situated as an active choice, signified through characteristics of observable behavior, whereas in others it is seen as an indelible category, typified by dispositions and characteristics like time of immigration and accent, which are not presented as readily changeable. In indexically linking social categories to values, mentality, and interior states of emotion rather than visible practices, this second 
discourse emphasizes the interiority of social positioning, as something which is held within oneself rather than achieved through outwardly directed behavior.

While the first kind of social positioning is usually linked to "ethnic options" and the second is linked to "racial labels," we have demonstrated that these two ideologies of identity operate independently of specific terms. Moreover, when we closely examine interactions themselves, it becomes apparent that the categories of self-ascription and other-imposition are slippery ones. People can describe themselves in ways that make it apparent that they are voicing other people's terms, and they can contest and challenge other people's descriptions of them. Successful identity ascriptions require both participants to recognize and accept an act of identity-making, whether it be initiated by the other or by the self.

In the end, the vision of race as something which is imposed from outside, but of ethnicity as a kind of free choice which Asian Pacific Americans can exercise within the safe space of the ethnic community is perhaps a bit romanticized. Pigeonholing does not take place only later in life, or only in outgroup situations, but can and does take place within the boundaries of what is usually considered a single ethnic community. By looking at how identities are negotiated between participants, a discourse analytic perspective can help us to better understand how self-ascription and other-imposition are not so much two ends of a continuum as they are dynamic processes which are always at play in any act of identity-making.

\section{Notes}


* Earlier versions of this paper were presented at the 2002 Association for Asian American Studies conference and at the 2002 American Anthropological Association conference. We would like to thank the participants at those sessions, especially Elaine Chun, Mary Bucholtz, Kyeyoung Park, and Esther Kim Choi, for their feedback and Alessandro Duranti and Angela Reyes for their thoughtful comments on earlier versions of this paper. This work was supported by grants from the UCLA Asian American Studies Center, the Spencer Foundation, and the University of California Linguistic Minority Research Institute (UC LMRI) under the UC LMRI Grants Program. Opinions reflect those of the authors and do not necessarily reflect those of the grant agencies. 1 Richard D. Alba, Ethnic Identity: The Transformation of White America (New Haven: Yale University Press, 1990); Mary C. Waters, Ethnic Options: Choosing Identities in America (Berkeley: University of California Press, 1990).

2 Herbert Gans, "Symbolic Ethnicity: The Future of Ethnic Groups in America," Ethnic and Racial Studies 2 (1979): 1-20.

3 Stephen E. Cornell and Douglas Hartmann, Ethnicity and Race: Making Identities in a Changing World. (Thousand Oaks, CA: Pine Forge Press, 1998).

4 Mary C. Waters, Black Identities: West Indian Immigrant Dreams and American Realities (New York; Cambridge, MA: Harvard University Press, 1999).

5 Richard Jenkins, "Rethinking Ethnicity: Identity, Categorization and Power," Ethnic and Racial Studies 17, no. 2 (1994): 197-223.

6 Yen Le Espiritu, Asian American Panethnicity: Bridging Institutions and Identities (Philadelphia: Temple University Press, 1992). 
7 Mia Tuan, Forever Foreigners or Honorary Whites?: The Asian Ethnic Experience Today (New Brunswick, NJ: Rutgers University Press, 1998), 21.

8 Nazli Kibria, Becoming Asian American: Second-Generation Chinese and Korean American Identities (Baltimore: Johns Hopkins University Press, 2002).

9 Miri Song, "Comparing Minorities' Ethnic Options: Do Asian Americans Possess 'More' Ethnic Options Than African Americans?," Ethnicities 1, no. 1 (2001): 57-82.

10 J. L. Austin, How to Do Things with Words (Oxford: Clarendon Press, 1962).

11 Lisa Lowe, Immigrant Acts: On Asian American Cultural Politics (Durham: Duke University Press, 1996).

12 Homi Bhabha, "The Third Space: Interview with Homi Bhabha," Identity:

Community, Culture, Difference, ed. Jonathan Rutherford (London: Lawrence \& Wishart, 1990), 207-221.

13 As Ochs and Capps explain, "Personal narrative is a way of using language or another symbolic system to imbue life events with a temporal and logical order, to demystify them and establish coherence across past, present, and as yet unrealized experience." Elinor Ochs and Lisa Capps, Living Narrative: Creating Lives in Everyday Storytelling (Cambridge, MA: Harvard University Press, 2001), 2.

14 For example, see Elinor Ochs and Carolyn Taylor, "Family Narrative as Political Activity," Discourse and Society 3, no. 3 (1992): 301-40; Elinor Ochs et al., "Storytelling as a Theory-Building Activity," Discourse Processes 15, no. 1 (1992): 37-72; Elinor Ochs and Carolyn Taylor, "The 'Father Knows Best' Dynamic in Dinnertime Narratives," Gender Articulated: Language and the Socially Constructed Self, ed. Kira Hall and Mary Bucholtz, (New York: Routledge, 1995), 97-120; Ochs 
and Capps, Living Narrative; Betsy Rymes, Conversational Borderlands: Language and Identity in an Alternative Urban High School (New York: Teachers College Press, 2001).

15 Lisa Capps and Elinor Ochs, Constructing Panic: The Discourse of Agoraphobia (Cambridge, MA: Harvard University Press, 1995), 18.

16 Michael Silverstein, "Shifters, Linguistic Categories, and Cultural Description," Meaning in Anthropology, ed. Keith Basso and Henry A. Selby, (Albuquerque, NM: University of New Mexico Press, 1976), 11-56.

17 Alessandro Duranti, Linguistic Anthropology (New York: Cambridge University Press, 1997), 19.

$18 \mathrm{We}$ are indebted to Alessandro Duranti for articulating this point.

19 Lisa Capps and Elinor Ochs describe this perspective in Constructing Panic: The Discourse of Agoraphobia (Cambridge, MA: Harvard University Press, 1995):

We view stories not as flawed renditions of reality but as windows into individual and collective theories of reality. In our view theories organize lives; they give meaning and coherence to ongoing experience. It is not what "really" happened but rather experiencers' theories of what happened that provide continuity between past, present, future, and imagined lives. (21)

20 While our respondents did offer definitions of particular terms, these were inconsistent. Frequently, we would ask about one term, and respondents would answer by giving a definition in terms of another one. A full analysis of what terms like "Korean Korean" or "Koreanized" mean would require looking at not only the definitions given in interviews, but at how such terms are used in interaction and how they accrue meaning in relation to each other as well. That task is beyond the scope of this paper. 
21 The term "fob" and its related adjectival form, "fobby," appear to be related to the term "F.O.B.," which our informants described as an acronym for "Fresh Off the Boat." We have chosen to spell the term as "fob" to reflect the way this word was pronounced by our interviewees.

22 Interview conducted March 7, 2003.

23 Gans, "Symbolic Ethnicity."

24 Interview conducted December 6, 2001.

25 See M. Agnes Kang, "Constructing Ethnic Identity through Discourse: SelfCategorization among Korean American Camp Counselors," Pragmatics 14, no. 2/3 (2004): 217-33 for a discussion of how terms such as "Korean," "Korean American," and "American" are indexed to particular stances and relationally positioned within a field of oppositions.

26 Interview conducted February 17, 2002.

27 Emanuel A. Schegloff, Gail Jefferson, and Harvey Sacks, "The Preference for SelfCorrection in the Organization of Repair in Conversation," Language 53 (1977): 361 82.

28 Interview conducted February 17, 2002.

29 Randolph Quirk et al., A Comprehensive Grammar of the English Language (London; New York: Longman, 1985), 200-203.

30 Interview conducted February 17, 2002.

31 Interview conducted March 8, 2003.

32 Interview conducted February 17, 2002.

33 Interview conducted February 17, 2002. 
34 Akhil Gupta and James Ferguson, "Culture, Power, Place : Ethnography at the End of an Era," Culture, Power, Place : Explorations in Critical Anthropology, ed. Akhil Gupta and James Ferguson (Durham, NC: Duke University Press, 1997), 1-29.

35 Interview conducted December 6, 2001.

36 Interview conducted March 7, 2003.

37 Pierre Bourdieu, The Logic of Practice (Stanford: Stanford University Press, 1990).

38 Though Bourdieu does not preclude the possibility that individuals act according to conscious, teleological decisions, this form of reasoning is secondary to the primary functions of habitus:

The conditionings associated with a particular class of conditions of existence produce habitus, systems of durable, transposable dispositions, structured structures predisposed to function as structuring structures, that is, as principles which generate and organize practices and representations that can be objectively adapted to their outcomes without presupposing a conscious aiming at ends or an express mastery of the operations necessary in order to attain them. Objectively 'regulated' and 'regular' without being in any way the product of obedience to rules, they can be collectively orchestrated without being the product of the organizing action of the conductor. It is, of course, never ruled out that the responses of the habitus may be accompanied by strategic calculation tending to perform in a conscious mode the operation that the habitus performs quite differently, namely an estimation of chances presupposing transformation of the past effect into an expected objective. But these responses are first defined, without any calculation, in relation to objective potentialities, immediately inscribed the present, things to do or not to do, things to say or not to say, in relation to a probable, 'upcoming' future (un a venir), which -- in contrast to the future seen as 'absolute possibility' (absolute Moglichkeit) in Hegel's (or Sartre's) sense, projected by the pure project of a 'negative freedom' -- puts itself forward with an urgency and a claim to existence that excludes all deliberation; Ibid., 53.

39 Erving Goffman, The Presentation of Self in Everyday Life (New York: Doubleday, 1959).

40 Quirk et al., A Comprehensive Grammar, 74. 
41 Dwight Le Merton Bolinger, Language, the Loaded Weapon: The Use and Abuse of Language Today (London; New York: Longman, 1980); Anna Wierzbicka, "What's in a Noun? (Or: How Do Nouns Differ in Meaning from Adjectives?)," The Semantics of Grammar (Amsterdam; Philadelphia: John Benjamins, 1988 [1986]), 463-97.

42 Bolinger, Language, the Loaded Weapon, 79.

43 Noun forms are also frequently far more negatively loaded than corresponding adjectives. As Bolinger points out in Language, the Loaded Weapon, insults are frequently performed through calling someone by a derogatory noun form. Thus, a person wishing to insult someone would say, "You're a Jap/Chink/Gook!" not, “You're Japanese/Chinese/Vietnamese!” (79)

44 Homi K. Bhabha, The Location of Culture (London; New York: Routledge, 1994).

45 Interview conducted December 6, 2001.

46 Interview conducted March 7, 2003.

47 Interview conducted December 6, 2001.

48 Quirk et al., A Comprehensive Grammar, 200.

49 Quirk et al., A Comprehensive Grammar, 404.

50 Interview conducted March 7, 2003.

51 Interview conducted December 6, 2001.

52 Interview conducted March 7, 2003.

53 Benjamin H. Bailey, "Dominican-American Ethnic/Racial Identities and United States Social Categories," International Migration Review 35, no. 3 (2001): 677-708.

54 Interview conducted December 6, 2001. 
55 Interview conducted December 6, 2001.

56 Interview conducted December 6, 2001.

57 M. M. Bakhtin, The Dialogic Imagination: Four Essays, trans. Caryl Emerson and Michael Holquist (Austin: University of Texas Press, 1981). 